\section{Die Föderalismusreform - ein absurdes Opfer, das sehenden Auges erbracht wurde}

Monika Frommel

n NK 1-2005, S. 6, hat Frieder Dünkel 12 Fragen an die damalige und heutige Justizministerin zur geplanten Verlagerung der Gesetzgebungskompetenz für den Strafvollzug auf die Länder gestellt, welche diese nicht beantwortet hat. Sie wusste warum. Die Anhörung der Experten im Bundestag am 17.05.2006

www.bundestag.de/aktuell/hib/ 2006/2006_151/05.html

hat erbracht, dass es kein einziges fachliches Argument gibt, das für die Länderzuständigkeit auf dem Gebiet des Strafvollzugs spricht. Beachtet wurde dies nicht. Nur das kurzfristige strategische Argument, dass Opfer erbracht werden müssen und sich diese Klientel nicht dagegen wehren kann, dass auf ihrem Rücken ein erbärmlicher Kuh-Handel betrieben wird. Dies lässt ahnen, wie es auf Länderebene nun weiter gehen kann, nämlich wenn auch dort das Bedürfnis nach symbolischer Politik alle fachlichen Einwände vom Tisch fegt.

Die Justizministerin hat sich dennoch nicht geschämt, am 5 . Juni bereits besprochenen RegierungsEntwurf vom 28.04.2006 für ein Jugendstrafvollzugs $\mathrm{G}$ erneut einzubringen, wissend, dass er am 30. Juni 2006 bereits Makulatur sein wird (vgl. Walter NK 1-2005, S. 17).

Hannelore Maelicke hat in NK 22005, S. 56 einen Nachruf auf Helga Einsele geschrieben. Rückblickend müsste man leider noch hinzufügen, dass mit dieser großartigen Kämpferin und dem Schweigen anderer großer Kriminalpolitiker die Epoche für eine rationale Kriminalpolitik im Jahre 2006 beendet worden ist. Kriminalpolitik der Finanzminister 2006 ihren in dieser Zeitschrift und Kosmetik für besorgte LandesjustizministerInnen wird die $\mathrm{Zu}$ kunft prägen. Die nächste Panne in einer Strafvollzugseinrichtung oder ein nicht zu verhinderndes Ereignis wird sie medial unter Druck setzen und die Landeszuständigkeit wird dann wieder ein zu billiges Argument für eine nur kurzfristig bedachte Modifikation sein. Die große Koalition hat ihre Mehrheit missbraucht. Die FDP hat immerhin mit einem prominenten Landesjustizminister in Baden-Württemberg ihr Votum im Bundestag bereits desavouiert. Politikverdrossenheit ist eine zu schwache Antwort bei so viel Unverfrorenheit. Wir werden versuchen im nächsten Heft der NK das, was geschehen ist, zu beschreiben und vielleicht gelingt es Regeln einzuführen, die das Geschehene mildern. Aber die Zeit der Strafrechtsreformen wird später einmal datiert werden mit 1968 - 2006.

\author{
Vorschau: \\ Heft 3/2006 erscheint im Oktober
}

\section{MPRESSUM}

Illustrationen und Photos

(Titel) Jan Frommel

Neue Kriminalpolitik erscheint in der

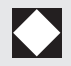

Nomos Verlagsgesellschaft, Baden-Baden

Druck und Verlag

Nomos Verlagsgesellschaft mbH \& Co. KG, Waldseestraße 3-5,

76530 Baden-Baden, Tel. (0 72 21)

21 04-0, Fax (0 72 21) 21 04-27

Anzeigenannahme:

sales friendly • Bettina Roos

Maarweg 48, 53123 Bonn

Tel. (0228) 978 98-0

Fax (0228) 978 98-20

roos@sales-friendly.de

Die Zeitschrift sowie alle in ihr enthaltenen einzelnen Beiträge und $\mathrm{Ab}$ bildungen sind urheberrechtlich geschützt. Jede Verwertung, die nicht ausdrücklich vom Urheberrechtsgesetz zugelassen ist, bedarf der vorherigen Zustimmung des Verlags. Dies gilt insbesondere für Vervielfältigungen,

Bearbeitungen, Übersetzungen, Mikroverfilmungen und die

Einspeicherung und Verarbeitung in elektronischem System.

Namentlich gezeichnete Artikel müssen nicht die Meinung der Herausgeber/Redaktion wiedergeben. Unverlangt eingesandte Manuskripte - für die keine Haftung übernommen wird - gelten als Veröffentlichungsvorschlag zu den Bedingungen des

Verlages. Es werden nur unveröffentlichte Originalarbeiten angenommen. Die Verfasser erklären sich mit einer nicht sinnentstellenden redaktionellen Bearbeitung einverstanden.

Erscheinungsweise: 4-mal jährlich; sowie dem Jahrbuch für Rechts- und Kriminalsoziologie am Jahresende und der Jahrgangs-CD-ROM.

Bezugsbedingungen: Abonnementspreis jährlich 68,- $€$ (inkl. MwSt.), Studentenabonnement $45,-€$ zuzüglich Porto und Versandkosten (zuzüglich MwSt. $7 \%$ ); Bestellungen nehmen entgegen: Der Buchhandel und der Verlag; Abbestellungen vierteljährlich zum Jahresende. Zahlungen jeweils im Voraus an: Nomos-Verlagsgesellschaft, Postbank Karlsruhe, Konto 73 636-751 und Stadtsparkasse Baden-Baden, Konto 5-002266 